\title{
LEONARDO BISSOLI
}

CONTROLE DA CORRUPÇÃO E DISCRICIONARIEDADE: OS MEIOS DE ACCOUNTABILITY DOS AGENTES PÚBLICOS E AS LICITAÇÕES E CONTRATAÇÕES PÚBLICAS

Dissertação de Mestrado

Orientador: Professor Doutor Sebastião Botto de Barros Tojal

UNIVERSIDADE DE SÃO PAULO

FACULDADE DE DIREITO

São Paulo - SP

2018 


\section{LEONARDO BISSOLI}

\section{CONTROLE DA CORRUPÇÃO E DISCRICIONARIEDADE: OS MEIOS DE ACCOUNTABILITY DOS AGENTES PÚBLICOS E AS LICITAÇÕES E CONTRATAÇÕES PÚBLICAS}

Dissertação apresentada à Banca Examinadora do Programa de Pós-Graduação em Direito, da Faculdade de Direito da Universidade de São Paulo, como exigência parcial para a obtenção do título de Mestre em Direito, na área de concentração Direito do Estado, sob a orientação do Professor Doutor Sebastião Botto de Barros Tojal.

UNIVERSIDADE DE SÃO PAULO

FACULDADE DE DIREITO

SÃo Paulo - SP

2018 


\section{Bissoli, Leonardo.}

Controle da corrupção e discricionariedade: os meios de accountability dos agentes públicos e as licitações e contratações públicas / Leonardo Bissoli; orientador Sebastião Botto de Barros Tojal - São Paulo, 2018.

262

Dissertação (Mestrado - Programa de Pós-Graduação em Direito do Estado) - Faculdade de Direito, Universidade de São Paulo, 2018.

1. Corrupção. 2. Accountability. 3. Discricionariedade. 4. Licitações e contratos administrativos. 5. Avaliação de riscos. I. Tojal, Sebastião Botto de Barros, orient. II. Título. 


\section{AGRADECIMENTOS}

Agradeço ao Professor Sebastião Botto de Barros Tojal pela orientação na elaboração do presente estudo.

Aos Professores Marcos Augusto Perez e Rodrigo Pagani de Souza, pelas importantes observações e contribuições na banca de qualificação.

Aos colegas do Tojal Renault Advogados, pelas discussões de ideias que nortearam os rumos da pesquisa e, principalmente, à Renata Rocha Villela, pelo precioso auxílio prestado para conclusão desta dissertação.

Por fim, à minha família, em especial à minha esposa, pelo incentivo e compreensão nos momentos de ausência. 
"The secret of great fortunes, when there's no obvious explanation for them, is always some forgotten crime -forgotten, mind you, because it's been properly handled."

Honoré de Balzac, Le Père Goriot, Paris, 1835. 


\section{RESUMO}

A globalização ampliou o fluxo de informações e o dinamismo nas relações sociais, políticas e econômicas, gerando um aumento exponencial de demandas sobre os Estados. O fenômeno da globalização também pautou a agenda de estudos relacionados à corrupção e caracterizou o direito sancionador como verdadeira Lex Mercatoria, destinada à regulação do mercado internacional. Essa nova concepção sobre a corrupção, a qual demanda rigorosos e complexos controles sobre as atividades dos agentes públicos, atua de forma decisiva na capacidade de ação do Estado, especialmente em relação aos países em desenvolvimento, uma vez que induz à produção de um discurso anticorrupção cujo pressuposto é a restrição da discricionariedade, elemento central para garantir flexibilidade de ação aos gestores públicos e, consequentemente, uma atuação eficiente da Administração Pública. No Brasil, o discurso anticorrupção, capturado pelo discurso político populista, produz uma cultura legislativa reativa a casos de corrupção, abalizada especialmente na fragilidade das instituições e na desconfiança nos agentes públicos, em especial, nos políticos. Com base nesse discurso, criam-se resistências, especialmente por parte dos órgãos de controle, à implantação de reformas na Administração e na legislação sobre licitações e contratos administrativos, mantendo-se assim vigente um modelo burocrático de gestão. Para viabilizar a saída do impasse estabelecido entre o controle da corrupção e uma gestão pública eficiente, o direito deve buscar formas de criar mecanismos de desincentivos ao ingresso de agente públicos e privados em relações de corrupção e, principalmente, formas de aprimorar a confiança nos agentes públicos. Propõe-se, no presente estudo, como forma de mitigar o risco à corrução no âmbito das licitações e contratos administrativos, o estímulo à livre concorrência e uma maior segurança jurídica no âmbito da execução dos contratos administrativos, por meio de uma relação mais horizontal entre o Estado e os particulares. Por fim, de modo a aprimorar a confiança nos agentes públicos e viabilizar a transposição dos controles formais para o de resultados, propõe-se a realização de uma avaliação de riscos à corrupção no âmbito das organizações, de modo que seja possível localizar os cargos e funções sensíveis à corrupção, o que permitiria direcionar, de forma estratégica, uma carga de controles específicos para prevenir e detectar atos de corrupção.

Palavras-chave: Corrupção; accountability; discricionariedade; licitações e contratos administrativos; avaliação de riscos. 


\begin{abstract}
Globalization has increased the flow of information and dynamism in social, political and economic relations, generating an exponential increase of demands for the States. The phenomenon of globalization also guided the agenda of studies related to corruption and characterized the sanctioning laws and procedures as a Lex Mercatoria, aimed at regulating the international market. This new conception of corruption, which demands rigorous and complex controls over the activities of public agents, plays a decisive role in the State's capacity for action, especially in relation to developing countries, since it induces the production of an anti-corruption discourse whose presupposition is the restriction of discretion, a central element to guarantee flexibility to the public managers and, consequently, an efficient performance of the Public Administration. In Brazil, the anticorruption discourse, captured by the populist political discourse, produces a reactive legislative culture in cases of corruption, based especially on the fragility of institutions and the distrust of public agents, especially politicians. Based on this discourse, resistances are created to the implementation of reforms in the Administration and legislation on bids and administrative contracts, especially by the control bodies, which colaborate to maintaining a bureaucratic management model. In order to make possible to overcome the impasse between corruption control and efficient public management, the law must seek ways to create disincentive mechanisms for the entry of public and private agents into corruption relations and, above all, ways of improving trust in public agents. Is proposed, in the present study, as a way of mitigating the risk of corruption in biddings and administrative contracts, the promotion of free competition and greater legal certainty in the execution of administrative contracts by means of a more horizontal relationship between the State and individuals. Finally, in order to improve the confidence on public agents and to make possible to transpose the formal controls to the results, it is proposed to carry out a risk assessment for corruption within organizations, so that it is possible to locate the positions and functions of risk, which would strategically direct a load of specific controls to prevent and detect acts of corruption.
\end{abstract}

Keywords: Corruption; accountability; discretion; biddings and administrative contracts; risks assessment. 


\section{SUMÁRIO}

1. INTRODUÇÃO.

\section{PERSPECTIVAS DE ANÁliSE DA CORRUPÇÃO: UM FENÔMENO COM MÚLTIPLAS ORIGENS E CONSEQUÊNCIAS...........................................................14}

2.1 PERSPECTIVA SOCIOCULTURAL DA CORRUPÇÃO..............................................17

2.1.1 A distinção ideológica entre os ambientes público e privado. .18

2.1.2 A impessoalidade como imperativo de separação das esferas pública e

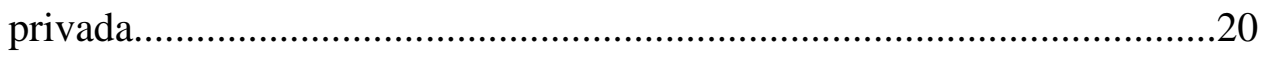

2.1.3 A construção da ideia de corrupção no Brasil.........................................22

2.1.4 A corrupção como fator de degradação da confiança nas instituições......30

2.2 PERSPECTIVA ECONÔMICO-POLÍTICA DA CORRUPÇÃO...........................................34

2.2.1 Fase da teoria da modernização..................................................................35

2.2.2 Da teoria da escolha racional à fase neoinstitucional...............................39

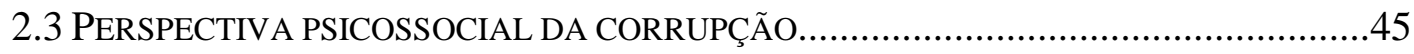

2.4 PERCEPÇÕES DA CORRUPÇÃO - A FRAGILIDADE DOS ESTUDOS EMPÍRICOS SOBRE O

TEMA. .48

2.5 A GLOBALIZAÇÃO DO COMBATE À CORRUPÇÃO. .51

2.5.1 O longo braço da jurisdição estadunidense sobre casos de corrupção. Padrão a ser seguido ou instrumento de dominação?. .58

2.5.2 Os efeitos da corrupção nas licitações e contratos administrativos e o seu enfrentamento globalizado.

2.6 CONCLUSÕES PARCIAIS. 72

\section{O ENQUADRAMENTO JURÍDICO DA CORRUPÇÃO E O SEU ENFRENTAMENTO NO ÂMBITO DO DIREITO SANCIONADOR.....................75}

3.1 ENQUADRAMENTO DA CORRUPÇÃO NO CAMPO JURÍDICO E UM POSSÍVEL MODELO TEÓRICO DE ANÁLISE. . .75

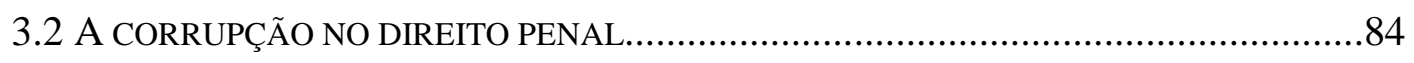

3.2.1 A caracterização da vantagem indevida e do ato de ofício.......................87

3.1.1.2 A globalização e a expansão do direito penal anticorrupção..................96

3.3 A CORRUPÇÃO NO DIREITO ADMINISTRATIVO...................................................99 
3.3.1 Corrupção e moralidade administrativa 106

3.3.2 Corrupção e discricionariedade administrativa. 115

3.3.3 O desenvolvimento do direito administrativo anticorrupção. 122

3.3.3.1 A consensualidade no combate à corrupção. 128

3.4 CONCLUSÕES PARCIAIS.

\section{A INFLUÊNCIA DO DISCURSO ANTICORRUPÇÃO NA ESTRUTURAÇÃO DO SISTEMA BRASILEIRO DE LICITAÇÕES E CONTRATOS

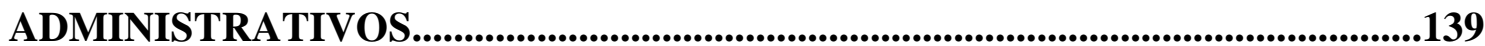

4.1 O DISCURSO ANTICORRUPÇÃO E OS SEUS EFEITOS SOBRE A EFICIÊNCIA DA ADMINISTRAÇÃO PÚBLICA.

4.1.1 As reformas realizadas no âmbito da Administração Pública brasileira, o discurso anticorrupção e a eficiência no exercício da função pública 145

4.2 O EMBATE ENTRE O MAXIMALISMO E O MINIMALISMO NA ESTRUTURAÇÃO DO SISTEMA DE LICITAÇÕES E CONTRATOS ADMINISTRATIVOS. 153

4.2.1 O início das licitações no Brasil sob modelos legais minimalistas. 155

4.2.2 A construção do modelo maximalista de licitações e contratos administrativos no Brasil....

4.2.3 As reações ao modelo maximalista baseadas na busca por maior eficiência no exercício da função pública. 166

$4.3 \mathrm{O}$ CONTROLE FORMALISTA E HIPERTROFIADO EM MATÉRIA DE LICITAÇÕES E CONTRATOS ADMINISTRATIVOS 173

4.3.1 A expansão do controle prévio dos atos da Administração Pública.......175

4.3.2 Os impasses do controle e o exercício da função administrativa.............181

4.4 A Resposta À Operação LAVA JATO - A Lei das Estatais E o COMBATE À

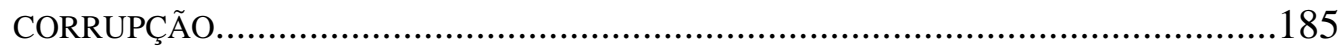

4.4.1 Diretrizes do regime licitatório previsto na Lei $\mathrm{n}^{\circ}$ 13.303/2016.............189 4.4.2 Introdução de mecanismos de governança corporativa e o risco de desvirtuamento das funções públicas das estatais.

4.5 AS POSSIBILIDADES E AS LIMITAÇÕES DO PROCESSO LICITATÓRIO E DOS CONTRATOS ADMINISTRATIVOS NO COMBATE À CORRUPÇÃO 206 4.5.1 A preponderância do princípio da ampla concorrência no combate à corrupção. 207 
4.5.2 A necessidade de maior segurança jurídica na execução dos contratos administrativos

5. PRESSUPOSTOS PARA A IDENTIFICAÇÃO DOS PROCESSOS E FUNÇÕES DE RISCO À CORRUPÇÃO - UM POSSÍVEL INSTRUMENTO DE BALANCEAMENTO DA DENSIDADE LEGISLATIVA SOBRE LICITAÇÕES E CONTRATOS ADMINISTRATIVOS........................................................................221

5.1 PANORAMA DO DESENHO INSTITUCIONAL DA ACCOUNTABILITY DOS AGENTES PÚBLICOS NO ORDENAMENTO JURÍDICO BRASILEIRO.. .224

5.2 O PODER DISCRICIONÁRIO DOS AGENTES PÚBLICOS DA LINHA DE FRENTE. .230

5.3 PRESSUPOSTOS PARA A IDENTIFICAÇÃO DOS PROCESSOS E FUNÇÕES DE RISCO À CORRUPÇÃO. .234

5.4 CONCLUSÕES PARCIAIS. 


\section{INTRODUÇÃO}

São Paulo, junho de 2013. Tudo transcorria para ser uma data como outra qualquer na capital paulista, apesar dos protestos contra o aumento das tarifas dos transportes públicos, catalisados pela visibilidade do país ante à proximidade da realização de importantes eventos esportivos e do pleito eleitoral de 2014. Entretanto, uma forte repressão policial a esses protestos provocou grande comoção popular e adesão às manifestações. A pauta dos protestos, antes direcionada ao aumento das tarifas, rapidamente transmutou-se para o tema da corrupção, o melhor instrumento para a população atingir o seu objeto de desconfiança e desgosto, a classe política.

Os agentes políticos, ao verem suas popularidades derreterem, adotaram o discurso anticorrupção reverberado pela sociedade para propor diversas alterações legislativas de modo a moralizar a gestão pública. Em um lapso de sorte para a sociedade, mas de azar para uma grande parte de agentes políticos, as medidas propostas pelo pacote legislativo anticorrupção de 2013 apresentaram-se como inovadoras, seja porque trouxeram novos mecanismos de prestação de contas e controles (accountability) dos agentes públicos e, especialmente, porque introduziram no âmbito do direito sancionador mecanismos de cooperação e transação, como os acordos de colaboração e de leniência. A partir do momento que esses novos mecanismos de enfrentamento da corrupção começaram a produzir efeitos, o tema tornou-se prioridade das agendas social, política e econômica do país, especialmente diante das revelações oriundas da Operação Lava Jato e suas decorrências.

Apesar de ter produzido resultado positivo ao pressionar a classe política a promover as alterações legislativas necessárias ao enfrentamento do problema, o discurso anticorrupção no Brasil começou a tomar formas messiânicas e fundamentalistas, sendo capturado por interesses escusos e produzindo resultados tão danosos à sociedade quanto a própria corrupção. Nesse sentido, o discurso de combate à corrupção, nos moldes atuais no Brasil, paralisa a gestão pública, impõem restrições ao desenvolvimento econômico e social, estabelece privilégios aos controladores em detrimento daqueles eleitos pelo povo e produz forte negação à atividade política.

Ocorre que, apesar de adquirir formas exacerbadas atualmente, o discurso anticorrupção não é novo no Brasil. Pelo contrário, sempre esteve presente na vida pública e fundamentou as reformas administrativas promovidas no País, bem como a estruturação 
das leis referentes à licitações e contratos administrativos. Entretanto, sempre encontrou em seu caminho um oponente, o discurso pela eficiência da gestão pública, sendo que o embate entre os dois ocorre em torno de um elemento: a discricionariedade administrativa.

Enquanto o discurso anticorrupção prega a restrição do poder discricionário dos agentes públicos, a imposição de múltiplos controles focados em aspectos formais e detalhistas, o discurso pela eficiência da gestão pública defende o oposto, ou seja, um maior campo para a atuação discricionária, tendo em vista a necessidade de flexibilidade para a ação dos gestores públicos, e a transposição da carga de controle de aspectos formais para a análise do cumprimento de metas e obtenção de resultados.

O conflito existente entre o controle da corrupção e a busca por maior eficiência na gestão pública é o pano de fundo do presente trabalho, e fundamenta a hipótese que norteará os caminhos da pesquisa, qual seja: que a manutenção do controle da Administração Pública sob o enfoque legalista e não de resultados decorre da ausência de confiança nos agentes públicos (necessária à efetiva implantação de um modelo gerencial de administração), que tem origem no contexto histórico de criação das normas de controle vigentes, no caso brasileiro, em um ambiente de combate a graves atos de corrupção por parte dos agentes públicos.

Dentre os objetivos da pesquisa, o principal é o de buscar caminhos para diminuir os trade-offs inerentes ao referido conflito, especialmente quando a escolha pela eficiência da Administração Pública pode gerar o risco de abertura para a incidência da corrupção. No caso, o objeto de análise será justamente onde mais este tipo de situação ocorre, que é no âmbito das licitações e contratos administrativos.

Para tanto, será necessário percorrer um longo caminho para estabelecer um desenvolvimento racional da agenda de pesquisas sobre a corrupção, a fim de compreender a sua relação com o tema da discricionariedade.

Nesse sentido, na Seção 2 realizaremos um levantamento histórico da evolução da agenda de pesquisas sobre a corrupção, bem como sobre as suas diversas perspectivas de análise e, especialmente, sobre o fenômeno da globalização do combate à corrupção e suas consequências aos países subdesenvolvidos, como o Brasil. Por uma questão metodológica, de forma a nos afastarmos de estudos que estejam contaminados por posições políticoideológicas em razão do cenário atual do país, esse levantamento será realizado com base precipuamente em literatura estrangeira e nas obras clássicas da literatura nacional. 
Na Seção 3, com o objetivo de estabelecer racionalidade jurídica ao tratamento do tema da corrupção, será proposta uma teoria para análise do fenômeno no âmbito do direito sancionador, como forma de trazer maior segurança jurídica e evitar a ocorrência de arbitrariedades e violações a direitos e garantias fundamentais.

Na Seção 4 serão analisados os efeitos do discurso anticorrupção na estruturação do sistema de licitações e contratos administrativos no Brasil, bem como as consequências do embate entre maximalistas e minimalistas na conformação das leis sobre o tema. Com o objetivo de estabelecer um equilíbrio entre o controle da corrupção e a eficiência na gestão administrativa, serão identificados os mecanismos que, no âmbito das licitações e contratos administrativos, podem ser utilizados para criar desincentivos à prática de atos de corrupção, em especial, o estímulo à ampla concorrência no âmbito das licitações e o estabelecimento de maior segurança jurídica na execução dos contratos administrativos por meio da promoção de maior horizontalidade na relação entre o Estado e os seus contratados.

Na Seção 5 proporemos um possível caminho para aprimorar a confiança nos agentes públicos e, consequentemente, viabilizar a transposição da carga de controles sobre aspectos formais para a análise de resultados, que é por meio da identificação de processos e funções de risco à corrupção. Tal mapeamento de riscos tem o condão de viabilizar o direcionamento estratégico das cargas de controle exatamente para aqueles pontos mais sensíveis à corrupção, o que certamente tende a colaborar para a prevenção e detecção de atos de corrupção, bem como auxilia no alívio da carga de controles formais sobre o restante da Administração Pública, permitindo assim uma atuação com maior flexibilidade por parte dos gestores públicos.

Por fim, após realizarmos as conclusões parciais ao término de cada Seção, a conclusão do presente trabalho se destinará a propor caminhos de forma a estabelecer um melhor equilíbrio entre o controle da corrupção e uma gestão pública eficiente. 


\section{CONCLUSÕES}

Após as conclusões parciais terem sido realizadas em cada seção, certamente o melhor norte para guiar as conclusões finais do presente estudo é tentar responder, com base no que foi produzido, à seguinte indagação: como é possível alcançar o equilíbrio ideal entre o controle da corrupção e a eficiência na gestão pública? Em nosso ver, a resposta tramita pelas seguintes considerações:

1 - O discurso anticorrupção sempre deve ser objeto de análise crítica.

A cultura legislativa reativa, oriunda do discurso anticorrupção, deve ser evitada. As propostas de alteração de leis e entendimentos que impliquem na adoção de maiores controles sobre o exercício da função administrativa devem ser precedidas da devida análise de custos e benefícios. Conforme restou exposto ao longo do presente estudo, o discurso anticorrupção é perene à infiltração de interesses escusos, os quais se utilizam do clamor popular para obter vantagens privadas, sendo a Lei $\mathrm{n}^{\circ}$ 8.666/1993 um exemplo claro desse cenário.

2 - As normas de controle devem sofrer constantes avaliações a fim de justificar a sua manutenção no sistema jurídico.

Como a consequência do discurso de combate à corrupção é a produção excessiva de normas destinadas ao controle dos agentes públicos, elas devem ser avaliadas periodicamente para verificar se: a) as razões para sua criação ainda existem; b) a corrupção à qual pretendem prevenir e combater é de alta relevância; c) existem razões para se acreditar que reduziram a ocorrência da corrupção à qual foram desenhadas à combater; d) não ocasionaram novas vulnerabilidades e formas de corrupção; e) não são desproporcionais em termos de custos para a eficiência da Administração em relação aos benefícios em reduzir a corrupção e; f) não há alguma estratégia ou mecanismo menos custoso para atingir o mesmo objetivo.

3 - O direito sancionador deve adotar um modelo de análise da corrupção como forma de manter a sua operacionalidade fechada

O fenômeno da corrupção tende a aumentar os influxos decorrentes dos demais sistemas ao sistema jurídico, induzindo muitas vezes a atividade jurisdicional a atuar de 
forma a esvaziar direitos e garantias fundamentais resguardados pela Constituição a fim de buscar uma maior "efetividade" ao processo sancionador. Tal fato causa uma disfuncionalidade no próprio sistema jurídico, que passa a operar de forma aberta, principalmente por meio das normas compostas de conceitos jurídicos indeterminados, o que, por consequência, produz indevida interferência nos demais sistemas, especialmente no econômico e no político. Assim, a definição de uma teoria sobre a corrupção no âmbito do direito sancionador torna-se fundamental para manter fechada a operacionalidade do sistema jurídico, mas também para resguardar direitos e garantias fundamentais e manter a autonomia da política e da gestão administrativa, que não pode ser conduzida pelas opções dos controladores ou dos juízes, sendo que, ao nosso ver, a teoria da agência adequa-se ao regime jurídico do direito sancionador e concede maior segurança jurídica para enfrentamento do problema, seja no âmbito penal ou no âmbito administrativo.

\section{4 - Técnicos e burocratas concursados não são imunes à corrupção;}

A criação de uma tecnocracia para gerir a Administração Pública não impede a prática de atos de corrupção, mas contribui para minar a confiança nas instituições políticas e fragiliza a democracia, uma vez que técnicos e burocratas não eleitos não prestam contas ao povo.

\section{5 - Regras formais e processuais não são capazes de coibir a corrupção}

A processualidade, embora seja um elemento importante para conferir legitimidade aos atos discricionários dos agentes públicos e viabilizar o seu controle posterior, não é suficiente, por si só, para evitar a prática de atos de corrupção. Processos formalmente hígidos, submetidos à consulta pública e aos mais diversos tipos de escrutínio podem ser, mesmo assim, lócus de relações corruptas.

\section{6-O principal objetivo das licitações públicas não é combater a corrupção}

A licitação nada mais é do que a criação de um mercado artificial, o qual não é baseado em leis da economia, mas sim em regras que estabelecem restrições à participação de fornecedores de produtos, obras e serviços por meio da imposição de requisitos de qualificação técnica, jurídica, econômica e financeira que têm, por origem, diversas razões de ser que não apenas a sua relação com o objeto licitado. Dessa forma, a premissa inicial que deve ser estabelecida em relação ao tema é a de que as regras sobre licitações e contratos administrativos não devem ter como objetivo principal o combate à corrupção, mas sim o de 
garantir a boa contratação para a Administração Pública, até mesmo porque, o simples fato de existirem regras de licitação já é um estímulo à corrupção, uma vez que elas representam restrições ao melhor mecanismo de combate à corrupção, que é a livre concorrência.

7 - O estímulo à concorrência e a imposição de maior segurança jurídica à execução dos contratos administrativos por meio da promoção da horizontalidade na relação entre Estado e contratado são os melhores caminhos para prevenir atos de corrupção no âmbito das licitações e contratações públicas

A ampla concorrência entre as empresas tem a capacidade de criar um ambiente de autofiscalização, de modo que nenhuma empresa, em uma economia de mercado (desde que não esteja cartelizado), aceitará a concessão de benefícios e privilégios indevidos aos seus concorrentes. Por sua vez, a promoção da horizontalidade da relação entre o Estado e os particulares, principalmente por meio do fim das denominadas "cláusulas exorbitantes", tem o condão de estabelecer maior segurança jurídica na execução dos contratos, o que, invariavelmente, atrairá mais interessados em contratar com a Administração, ampliando a concorrência nos certames.

8-É essencial o aprimoramento da confiança nos agentes públicos, em especial, nos políticos;

O aprimoramento da confiança nos agentes públicos é, ao nosso ver, o ponto chave para viabilizar o deslocamento da carga de controles sobre aspectos formais dos atos da Administração Pública para a verificação do cumprimento de metas e resultados. Ou seja, para a efetividade da implantação do modelo gerencial de Administração, são necessárias reformas a fim de aumentar a confiança nos gestores públicos, as quais podem ser realizadas no plano macro, como a reforma política, e no plano micro, por meio da identificação de processos de risco à corrupção e, consequentemente, dos cargos que executam funções no âmbito de tais processos.

9 - A discricionariedade é elemento essencial para viabilizar uma Administração Pública eficiente;

A discricionariedade é elemento fundamental para viabilizar uma atuação eficiente por parte da Administração. Entendimento contrário pressuporia que a lei, por si só, seria capaz de prever e regulamentar, de forma objetiva, todas as relações sociais, políticas e econômicas existentes no âmbito de uma sociedade complexa, o que de fato é impossível, 
tendo em vista que o sistema jurídico não é autopoiético. Assim, não há como se afastar a necessidade do exercício do poder discricionário por parte dos agentes públicos como forma de garantir à Administração a flexibilidade necessária ao atendimento de todas as demandas que lhe são direcionadas.

\section{0 - Todo agente público tem e exerce poder discricionário}

Todo agente público tem margem para exercer atos discricionários no cumprimento de suas funções, em especial, os agentes públicos da linha de frente, os quais, inclusive, são obrigados a exercê-los na implementação de políticas públicas.

11 - As cargas de controle devem ser estrategicamente direcionadas às funções de risco à corrupção

O mapeamento das funções de risco à corrupção poderia auxiliar no direcionamento estratégico das cargas de controle específicas à prevenção e detecção de atos de corrupção, o que certamente traria bons resultados e, consequentemente, viabilizaria a transposição dos controles formais sobre a Administração para a análise de metas e resultados.

De forma a concluir o presente trabalho, essas são algumas premissas que podem colaborar no estabelecimento de um correto balanço entre o controle da corrupção e a necessária eficiência à gestão pública. Certamente a academia ainda tem muito a contribuir sobre essa temática, especialmente de forma a buscar métodos para a realização de testes empíricos capazes de comprovar a efetividade dos mecanismos de accountability dos agentes públicos no enfrentamento da corrupção, sem a utilização, para tanto, de índices de percepção como instrumento de constatação de resultados, uma vez que, conforme ressaltamos desde o início do presente trabalho, a subjetividade dessas percepções geralmente produz falsos resultados, os quais servem unicamente como combustível a um infundado discurso anticorrupção. 


\section{REFERÊNCIAS BIBLIOGRÁFICAS}

ABRAMO, Claudio Weber. Percepções pantanosas: a dificuldade de medir a corrupção. In Novos estudos - CEBRAP, São Paulo, n. 73, p. 33-37, Nov. 2005. Disponível em: http://www.scielo.br/scielo.php?script=sci_arttext\&pid=S0101$\underline{33002005000300003 \& \operatorname{lng}=\mathrm{en} \& \mathrm{nrm}=\mathrm{iso}}$. Acesso em 29 de agosto de 2017. http://dx.doi.org/10.1590/S0101-33002005000300003.

ABRUCIO, Fernando Luiz. Trajetória Recente da Gestão Pública Brasileira: Um Balanço Crítico e a Renovação da Agenda de Reformas. In Revista de Administração Pública, vol. 41, edição especial comemorativa, 2007, pp. 67-86.

ADES, Alberto; DI TELLA, Rafael. Rents, competition, and corruption. In The american economic review, vol. 89, setembro de 1999, pp. 982-993. Disponível em: 〈www.people.hbs.edu/rditella/papers/AERRentsCorruption.pdf $>$. Acesso em 05 de janeiro de 2018.

ANECHIARICO, Frank; JACOBS, James. The pursuit of absolute integrity. How corruption control makes government inneffective. Chicago: The University of Chicago Press: 1996.

ARAUJO JR., Ari Francisco de. Raízes econômicas da criminalidade violenta no Brasil: um estudo usando micro dados e pseudopainel - 1981/1996. In Revista de Economia e Administração, v. 1, n. 3, p. 1-34, 2002. Disponível em: < http://www.spell.org.br/documentos/ver/25578/raizes-economicas-da-criminalidadeviolenta-no-brasil--um-estudo-usando-micro-dados-e-pseudopainel---1981-1996/i/pt-br>. Acesso em 20 de junho de 2017.

ARENDT, Hannah. A condição humana. 10ª edição. Rio de Janeiro: Forense Universitária, 2007.

AVRITZER, Leonardo; BIGNOTTO, Newton; GUIMARÃES, Juarez; STARLING, Heloisa Maria (orgs.). Corrupção - Ensaios e Críticas. Belo Horizonte: Editora UFMG, 2008 .

AZEVEDO, Sandson Barbosa; GERVASIO, Tamires Cunha. A percepção da aplicabilidade da lei de conflito de interesses por servidores da Controladoria-Geral da União. In Periódico Científico Negócios em Projeção, vol. 5, n. 1, jun. 2014, págs. 22-40. 
BARACUI, Pedro Lehmann. Estudo de conformidade do ambiente brasileiro com a Convenção Interamericana Contra Corrupção da OEA. Disponível em: <https://www.transparencia.org.br/docs/Estudo.pdf>. Acesso em 07 de setembro de 2017.

BARBACETTO, Gianni; GOMEZ, Peter; TRAVAGLIO, Marco. Operação mãos limpas: a verdade sobre a operação italiana que inspirou a lava Jato. Porto Alegre: CDG, 2016.

BARROS FILHO, Clóvis; PRAÇA, Sérgio. Corrupção. Parceria degenerativa. Campinas: Papirus 7 Mares, 2014.

BECKER, Gary Stanley. Crime and Punishment: An Economic Approach. In The Journal of Political Economy, v. 76, n. 2, março/abril de 1968, p. 169-217. Disponível em: < http://www.nber.org/chapters/c3625>. Acesso em 20 de junho de 2017.

BINENBOJM, Gustavo. Poder de polícia, ordenação e regulação: transformações politicojurídicas, econômicas e institucionais do direito administrativo ordenador. $2^{\mathrm{a}}$ ed. Belo Horizonte: Fórum, 2017

BOBBIO, Norberto. O futuro da democracia: uma defesa das regras do jogo. Tradução Marco Aurélio Nogueira. Rio de Janeiro: Paz e Terra, 1992.

BOBBIO, Norberto; MATTEUCCI, Nicola; PASQUINO, Gianfranco; Dicionário de política. tradução Carmen Varriale. Brasília: Editora Universidade de Brasília, 1998.

BRASIL. 1 ${ }^{\text {a }}$ Vara Federal de Curitiba - PR. Ação de Improbidade $n^{\circ}$ 502595671.2016.4.04.7000. Evento 187. Disponibilizado em 24 de março de 2017. Disponível em http://www.trf4.jus.br/trf4/processos/verifica.php, mediante o preenchimento do código verificador 700003122957v81 e do código CRC 937437d8. Acesso em 09 de dezembro de 2017.

BRASIL. Senado Federal. Notas taquigráficas da 30ª Sessão Deliberativa Ordinária de 15 de março de 2016. Disponível em: <https://www25.senado.leg.br/web/atividade/notastaquigraficas/-/notas/s/3727> . Acesso em 05 de janeiro de 2018.

BRASIL. Advocacia-Geral da União. Parecer GQ-124. Publicado no Diário Oficial da União em 30 de maio de 1997, p. 11.182. Disponível em <http://www.agu.gov.br/atos/detalhe/8303 > . Acesso em 08 de novembro de 2017. 
BRASIL. Controladoria-Geral da União; Transparência Brasil. Metodologia de Mapeamento de Riscos à Corrupção. Disponível em: <https://www.transparencia.org.br/docs/maparisco.pdf $>$. Acesso em 12 de janeiro de 2018. BRASIL. Tribunal de Contas da União. Glossário de termos do controle externo. Brasília: TCU, 2012, pp. 9 e 13. Disponível em: <http://portal.tcu.gov.br/comunidades/fiscalizacaoe-controle/normas-de-auditoria-do-tcu/normas-de-auditoria-do-tcu.htm>. Acesso em $30 \mathrm{de}$ dezembro de 2017.

BRESSER-PEREIRA, Luiz Carlos. Gestão do Setor Público: Estratégia e Estrutura para um Novo Estado. In BRESSER-PEREIRA, Luiz Carlos; SPINK, P. (orgs.), Reforma do Estado e Administração Pública Gerencial. Rio de Janeiro: Editora da FGV, 2001, pp. 2138.

BRESSER-PEREIRA, Luiz Carlos. Reforma do Estado para a cidadania: a reforma gerencial brasileira na perspectiva internacional. São Paulo: Ed. 34, 2011.

BUCCI, Maria Paula Dallari. Direito Administrativo e Políticas Públicas. São Paulo: Saraiva, 2002.

BUCCI, Maria Paula Dallari. Fundamentos para uma Teoria Jurídica das Políticas Públicas. São Paulo: Saraiva, 2013.

CALLEGARI, André Luís; WEBER, Ariel Barazzetti. Lavagem de dinheiro. São Paulo: Atlas, 2014.

CAMMAROSANO, Márcio. A aplicação do conceito de patrimônio público e sua proteção. In SUNDFELD, Carlos Ari; BUENO, Cássio Scarpinella (coords.). Direito processual público - a Fazenda Pública em juízo. São Paulo: Malheiros, 2000.

CAMMAROSANO, Márcio. O princípio constitucional da moralidade e o exercício da função administrativa. Belo Horizonte: Fórum, 2006.

CAMPANTE, Rubens Goyatá. O patrimonialismo em Faoro e Weber e a sociologia brasileira. In Dados - Revista de Ciências Sociais, v.46, n²1, 2003, pp. 153-193. Disponível em: <http://www.scielo.br/pdf/dados/v46n1/a05v46n1.pdf > . Acesso em 13 de novembro de 2017.

CAMPILONGO, Celso Fernandes. $O$ direito na sociedade complexa. $2^{\mathrm{a}}$ edição. São Paulo: Saraiva, 2011. 
CAMPOS, Marcelo da Silveira. Escolha racional e criminalidade: uma avaliação crítica do modelo. In R.SJRJ, n. 22. Rio de Janeiro, 2008, p. 93-110. Disponível em: $<$ http://www.observatoriodeseguranca.org/files/escolha.pdf $>$. Acesso em 20 de junho de 2017.

COUTINHO, Diogo Rosenthal. $O$ direito nas políticas públicas. Disponível em: $<$ https://edisciplinas.usp.br/pluginfile.php/2823006/mod_resource/content/1/1.2.\%200\%20 direito\%20nas\%20políticas\%20públicas\%20-\%20Diogo\%20Coutinho.pdf>. Acesso em: 22 de dezembro de 2017.

DALLARI, Adílson Abreu. Limitações à atuação do Ministério Público na Ação Civil Pública. In Improbidade administrativa. Questões polêmicas e atuais. São Paulo: Malheiros, 2001, pp. 19-41.

DI PIETRO, Maria Sylvia Zanella. Direito Administrativo. 24. ed.. São Paulo: Atlas, 2011.

DI PIETRO, Maria Sylvia Zanella. Discricionariedade administrativa na Constituição de

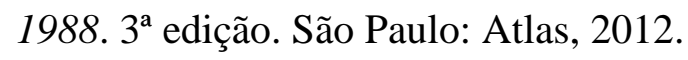

DINO. Nicolao. A colaboração premiada na improbidade administrativa: possibilidade e repercussão probatória. In SALGADO, Daniel de Resende; QUEIROZ, Ronaldo Pinheiro de (org.). A prova no enfrentamento à macrocriminalidade. Salvador: JusPodium, 2015. DOWDLE, Michael W.. Anti-Anti-corruption. Part I. Disponível em < http://lawdevelopment.blogspot.com.br/2014/04/anti-anti-corruption-part-i.html>. Acesso em 17 de setembro de 2017.

ELSTER, Jon. The Cement of Society. A Study of Social Order. Cambridge: Cambridge, 1989.

FAORO, Raymundo. Os Donos do Poder - formação do patronato político brasileiro. $5^{\text {a }}$ ed., São Paulo: Globo.

FERNÁNDEZ, Miguel Bajo; BACIGALUPO, Silvina. Politica criminal y blanqueo de capitales. Madrid: Marcial Pons, 2009.

FERREIRA FILHO, Manoel Gonçalves. A corrupção como fenômeno social e político. In Revista de Direito Administrativo, Rio de Janeiro, v. 185, p. 1-18, jul. 1991. Disponível em: <http://bibliotecadigital.fgv.br/ojs/index.php/rda/article/view/44482/47693>. Acesso em 18 de setembro de 2017. doi:http://dx.doi.org/10.12660/rda.v185.1991.44482. 
FILGUEIRAS, Fernando. A tolerância à corrupção no Brasil: uma antinomia entre normas morais e prática social. In Opinião Pública, v. 15, n. 2, 2009. p. 386-421.

FILGUEIRAS, Fernando; MELO ARANHA, Ana Luiza. Controle da Corrupção e Burocracia da Linha de Frente: Regras, Discricionariedade e Reformas no Brasil. In DADOS - Revista de Ciências Sociais, Rio de Janeiro, vol. 54, nº. 2, 2011, pp. 349-387;

FREUND, Julien. A sociologia de Max Weber. Rio de Janeiro: Forense Universitária, 1975. FURTADO, Lucas Rocha. As raízes da corrupção no Brasil - Estudo de casos e lições para o futuro. Belo Horizonte: Fórum, 2015.

GARRETT, Brandon L. Too big to jail: how prosecutors compromisse with corporations. Cambridge: The Belknap Press of Harvard University Press, 2014.

GUERRA, Sérgio. Discricionariedade, regulação e reflexividade: uma nova teoria sobre as escolhas administrativas. 4ª edição. Belo Horizonte: Fórum, 2017.

GORTA, Angela. Corruption Risk Areas and Corruption Resistance. In Measuring Corruption (Law, Ethics and Governance), Burlington: Ashgate Publishing, 2006.

GRAU, Eros Roberto. $O$ direito posto e o direito pressuposto. $7^{a}$ edição. São Paulo: Malheiros, 2008.

HANNA, Rema; WANG, Shing-Yi. Dishonesty and selection into public service. Disponível em < http://www.nber.org/papers/w19649>. Acesso em 20 de agosto de 2017.

HOLANDA, Sérgio Buarque de. Raízes do Brasil. São Paulo: Companhia das Letras, 2016. HOUAISS, Antônio; VILLAR, Mauro de Salles. Dicionário Houaiss da língua portuguesa. Elaborado por Instituto Antônio Houaiss de Lexicografia e Banco de Dados da Língua Portuguesa S/C Ltda. Rio de Janeiro: Objetiva, 2009.

HUNGRIA, Nelson. Comentários ao Código Penal. 2ª ed.. Rio de Janeiro: Forense, 1959, v. IX.

HUNTINGTON, Samuel P. Political order in changing societies. New Haven, Yale University Press, 1968.

ICAC, Independent Commission Against Corruption. Profiling The New Public Sector: Functions, Risks and Corruption Resistance Strategies. 2003. Disponível em: http://www.icac.nsw.gov.au/documents/preventing-corruption/research-1/1665-profiling- 


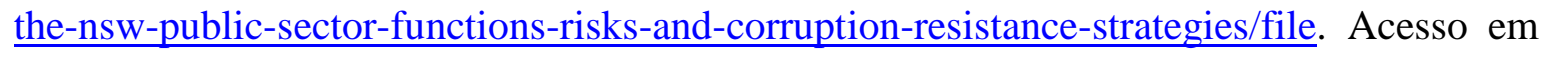
12 de janeiro de 2018.

JORDÃO, Eduardo. A intervenção do TCU sobre editais de licitação não publicados: controlador ou administrador? In Revista Brasileira de Direito Público - RBDP, Belo Horizonte, ano 12, n. 47, pp. 209-230, out./dez. 2014.

JUSTEN FILHO, Marçal. Apresentação. In JUSTEN FILHO, Marçal (org.) Estatuto jurídico das empresas estatais: Lei 13.303/2016. São Paulo: Editora Revista dos Tribunais, 2016, pp. 9-12.

KEYNES, John Maynard. Teoria geral do juro, do emprego e da moeda. Tradução de Mário R. da Cruz. São Paulo: Editora Nova Cultural Ltda., 1996. Disponível em: <http://www.ie.ufrj.br/intranet/ie/userintranet/hpp/arquivos/090320170036_Keynes_Teoria Geraldoempregodojuroedamoeda.pdf>. Acesso em 05 de janeiro de 2018.

KJELLBERG, Francesco. Conflict of interest, corruption or (simply) scandals? In Crime, Law and Social Change, v. 22, n. 4, p. 339-360, 1994. APA.

KLITGAARD, Robert. Controlling Corruption. Los Angeles: University of Califórnia Press, 1988.

KLITGAARD, Robert. Internacional cooperation against corruption. In Finance \& Development, mar. $1998 . \quad$ Disponível em: <https://www.imf.org/external/pubs/ft/fandd/1998/03/pdf/klitgaar.pdf. $>$. Acesso em 20 de junho de 2016.

LAFER, Celso. O significado de república. Estudos históricos, Rio de Janeiro, v. 2, nº . 4, p. 222, 1989.

LAMBSDORFF, Johann Graf. Institucional Economics of Corruption and Reform. Cambridge: Cambridge University Press, 2007.

LAZZARINI, Sérgio. Capitalismo de laços: os donos do Brasil e suas conexões. Rio de Janeiro: Elsevier, 2011.

LEFF, Nathaniel H. Economic development through bureaucratic corruption. In American Behavioral Scientist, v. 8, n. 3, nov.1964, pp. 8-14. 
LEVY, Evelyn. Controle social e controle de resultados: um balanço dos argumentos e da experiência recente. In O público não-estatal na reforma do Estado. FGV. Rio de Janeiro, 1999.

LIPSKY, Michael. Street-Level Bureaucracy. Dilemas of the Individual in Public Services. New York: Russell-Sage Foundation, 2010.

LISCIANDRA, Maurizio. A Review of the Causes and Effects of Corruption in the Economic Analysis. In Organized Crime, Corruption and Crime Prevention. Springer International Publishing, 2014. pp. 187-195. Disponível em: http://papers.ssrn.com/sol3/papers.cfm?abstract_id=2372579. Acesso em 20 de junho de 2016.

LIVIANU, Roberto. Corrupção - incluindo a Lei Anticorrupção. $2^{\mathrm{a}}$. ed.. São Paulo: Quartier Latin, 2014.

LOMBA, Pedro. Teoria da responsabilidade política. Coimbra: Coimbra Editora, 2008.

MARCELINO, Gileno Fernandes. Em Busca da Flexibilidade do Estado: O Desafio das Reformas Planejadas no Brasil. In Revista de Administração Pública, vol. 37, no 3, pp. 641-659.

MARQUES NETO, Floriano de Azevedo; PALMA, Juliana Bonacorsi de. Os sete impasses do controle da administração pública no Brasil. In PEREZ, Marcos Augusto; SOUZA, Rodrigo Pagani de. Controle administração pública. Belo Horizonte: Fórum, 2017, pp. 2138.

MARQUES NETO, Floriano de Azevedo; PALMA, Juliana Bonacorsi de. Licitação nas empresas estatais - os desafios do novo regime das licitações na Lei das Empresas Estatais (Lei $n^{o}$ 13.303/2016). In NORONHA, João Otávio de; FRAZÃO, Ana; MESQUITA, Daniel Augusto (Coord.) Estatuto jurídico das estatais: análise da Lei $\mathbf{n}^{\mathbf{0}} \mathbf{1 3 . 3 0 3 / 2 0 1 6}$. Belo Horizonte: Fórum, 2017, pp. 245-270.

MASHAW. Jerry L. Accountability and institucional design: some thoughts on the gramar of governance. In DOWDLE, Michael W. Public accountability: designs, dilemmas and experiencies. Cambridge: Cambridge University Press, 2006, pp. 115-156.

MAURO, Paolo. Corruption and growth. In The Quarterly Journal of Economics, vol. 110, $\mathrm{n}^{\mathrm{o}}$. 3, ago. 1995, pp. 681-712. Disponível em: 
http://homepage.ntu.edu.tw/ kslin/macro2009/Mauro\%201995.pdf. Acesso em: 26 de junho de 2016.

MEDAUAR. Odete. A processualidade no direito administrativo. $2^{\text {a }}$ edição. São Paulo: Revista dos Tribunais, 2008.

MEDAUAR. Odete. Direito Administrativo Moderno. 13a ed., São Paulo: Editora Revista dos Tribunais, 2009.

MESSICK, Rick. รั่วาดขัของอ: The Laotian Approach. Disponível em: <https://globalanticorruptionblog.com/2016/07/20/รั่วาดบัตขูอง-the-laotian-approach/>. Acesso em 07 de agosto de 2017.

MILGRAM, Stanley. Obedience to authority: an experimental view. New York: Harper \& Row, 1974.

MIRABETE, Júlio Fabbrini. Manual de Direito Penal. 21ª ed.. São Paulo: Atlas, 2006, v. 1.

MIRABETE, Júlio Fabbrini. Manual de Direito Penal. 21ª . ed.. São Paulo: Atlas, 2006, v. 3.

MOISÉS, José Álvaro (org.), Democracia e Confiança - Por que os cidadãos desconfiam das instituições públicas?. São Paulo: EdUSP, 2010.

MORO, Sérgio Fernandes. Considerações sobre a operação Mani Pulite. In R. CEJ, Brasília, n. 26, jul./set. 2004, pp. 56-62. Disponível em: http://jornalggn.com.br/sites/default/files/documentos/art20150102-03.pdf. Acesso em 27 de junho de 2016.

MUDDE, Cas. The Populist Zeitgeist: government \& opposition. Malden: Blackwell Publishing, 2004. Disponível em: 〈http://works.bepress.com/cas_mudde/6/>. Acesso em 02 de janeiro de 2018.

NOHARA, Irene. Solução fácil de culpar a burocracia pela corrupção: não é simples assim. Disponível em: <http://esdp.net.br/solucao-facil-de-culpar-a-burocracia-pela-corrupcaonao-e-simples-assim/>. Acesso em 19 de dezembro de 2017.

NUCCI, Guilherme de Souza. Corrupção e anticorrupção. Rio de Janeiro: Forense, 2015. 
NYE, Joseph. Corruption and Political Development: a cost-benefit analysis. In American Political Science Review, Los Angeles, v.61, n.4, 1967, pp. 417-427.

OLIVEIRA, Antônio. Burocratas da linha de frente: executores e fazedores das políticas públicas. Rev. Adm. Pública, Rio de Janeiro, v. 46, n. 6, p. 1551-1573, dez. 2012, pp. 1554-1555. Disponível em: $<$ http://www.scielo.br/scielo.php?script=sci_arttext\&pid=S003476122012000600007\&lng=pt\&nrm=iso $>$. Acesso em $12 \mathrm{de}$ janeiro de 2018. <http://dx.doi.org/10.1590/S0034-76122012000600007>.

OLIVEIRA, Gustavo Henrique Justino de. Contrato de gestão. São Paulo: Revista dos Tribunais, 2008.

OLIVEIRA, Gustavo Henrique Justino de; SCHWANKA, Cristiane. A Administração Consensual como a Nova Face da Administração Pública no séc. XXI: fundamentos dogmáticos, formas de expressão e instrumentos de ação. In Revista da Faculdade de Direito da Universidade de São Paulo, v. 104, 2009.

OSÓRIO, Fábio Medina. Teoria da improbidade administrativa: má gestão pública, corrupção, ineficiência. $3^{\text {a }}$ ed. 2013. São Paulo: Revista dos Tribunais.

PAGOTTO, Leopoldo Ubiratan Carreiro. O combate à corrupção: a contribuição do direito econômico. 2010. Tese (Doutorado em Direito Econômico e Financeiro) - Faculdade de Direito, Universidade de São Paulo, São Paulo, 2010. doi:10.11606/T.2.2010.tde-21112011103454.

PALMA, Juliana Bonacorsi de. O que o TCU tem a dizer sobre acordos administrativos? Disponível em: <https://jota.info/colunas/controle-publico/o-que-o-tcu-tem-a-dizer-sobreacordos-administrativos-15112017>. Acesso em 05 de dezembro de 2017.

PEREZ, Marcos Augusto. Controle da discricionariedade administrativa. In PEREZ, Marcos Augusto; SOUZA, Rodrigo Pagani de. Controle da administração pública. Belo Horizonte: Fórum, 2017, pp. 63-82.

PIGA, Gustavo. A fighting chance against corruption in public procurement? In International Handbook on the Economics of Corruption, v.2, 2011, pp. 141-181. Disponível em http://www.gustavopiga.it/wordpress/wp-content/uploads/2012/01/Ch5.pdf. Acesso em 27 de junho de 2016. 
PINTO, Marcos Vinicius. Reflexões sobre improbidade administrativa, ônus da prova, modelos de constatação e nota sobre o NCPC. In BEDAQUE, José Roberto dos Santos; CINTRA, Lia Carolina Batista; EID Elie Pierre (coord.). Garantismo processual: garantias constitucionais aplicadas ao processo. São Paulo: Gazeta Jurídica, 2016.

PITOMBO. Antônio Sérgio A. de Moraes. Lavagem de dinheiro: a tipicidade do crime antecedente. São Paulo: Revista dos Tribunais, 2003.

PORTA, Donatella della; VANNUCCI, Alberto. The 'Perverse Effects' of Political Corruption. In Political Studies, v. 45, 1997.

PORTA, Donatella della; VANNUCCI, Alberto. The hidden order of corruption: an institucional approach. New York: Routledge, 2016.

PRATS I CATALÁ, Joan. Direito e gerenciamento nas administrações públicas: notas sobre a crise e renovação dos respectivos paradigmas. In Revista do Serviço Público, v. 120, nº 2, mai/ago 1996, pp. 23-46.

RESENDE, Flavio da Cunha. Por que as reformas administrativas falham? In Revista Brasileira de Ciências Sociais, Vol. 17, nº 50, pp. 123-184.

RODRIGUES, Maria Alice. Os arranjos normativos e institucionais subjacentes à revisão da legislação sobre licitações e contratos administrativos. 2016. Dissertação (Mestrado em Direito do Estado) - Faculdade de Direito, Universidade de São Paulo, São Paulo, 2016.

ROSE-ACKERMAN, Susan. Corruption: a study in political economy. New York: Academic Press, 1978.

ROSE-ACKERMAN, Susan. Corruption and government: causes, consequences and reform. New York: Cambridge University Press, 1999.

ROSE-ACKERMAN, Susan. A economia política da corrupção. In ELLIOT, Kimberly Ann (Org.). A corrupção e a economia global. Tradução de Marsel Nascimento Gonçalves de Souza. Brasília: UNB, 2002, pp. 50-102.

ROSE-ACKERMAN, Susan; PALIFKA, Bonnie J.. Corruption and government: causes, consequences and reform. $2^{\mathrm{a}}$ ed., New York: Cambridge University Press, 2016. 
ROSILHO. André. $O$ regime diferenciado de contratações/RDC e seu controle. In SUNDFELD, Carlos Ari (org.). Contratações públicas e seu controle. São Paulo: Malheiros, 2013, pp. 143-174.

ROSILHO, André. Licitação no Brasil. São Paulo: Malheiros, 2013.

SILVA, José Afonso da. Perspectivas das formas políticas. In Estudos em homenagem a Miguel Seabra Fagundes. Belo Horizonte: Del Rey, 1995.

SILVA, José Afonso da. Curso de direito constitucional positivo. $26^{\mathrm{a}}$ edição. São Paulo: Malheiros, 2006.

SILVEIRA, Renato de Mello Jorge; SAAD-DINIZ, Eduardo. Compliance, Direito Penal e Lei Anticorrupção. São Paulo: Saraiva, 2015.

SØREIDE, Tina. Corruption in public procurement: causes, consequences and cures. Report Chr. Michelsen Institutefaceboo. Disponível em: $<$ https://www.researchgate.net/publication/37166541_Corruption_in_public_procurement Causes_consequences_and_cures $>$. Acesso em 05 de janeiro de 2018.

SOUZA, Rodrigo Pagani de. Em busca de uma administração pública de resultados. In PEREZ, Marcos Augusto; SOUZA, Rodrigo Pagani de. Controle administração pública. Belo Horizonte: Fórum, 2017, pp. 39-61.

STEPHENSON, Matthew. Mauro (1995) does not show that corruption slows growth. Disponível em: < https://globalanticorruptionblog.com/2014/05/15/mauro-1995-does-notshow-that-corruption-is-bad-for-growth/> Acesso em 03 de setembro de 2017.

SUNDFELD, Carlos Ari. Contratações públicas e o princípio da concorrência. In SUNDFELD, Carlos Ari (org.). Contratações públicas e seu controle. São Paulo: Malheiros, 2013, pp. 15-41.

SUNDFELD, Carlos Ari; SOUZA, Rodrigo Pagani de. Licitação nas estatais: levando a natureza empresarial a sério. In SUNDFELD, Carlos Ari (org.). Contratações públicas e seu controle. São Paulo: Malheiros, 2013, pp. 79-101.

SUNDFELD, Carlos Ari; CÂMARA, Jacintho Arruda. Competência de controle dos Tribunais de Contas. In SUNDFELD, Carlos Ari (org.). Contratações públicas e seu controle. São Paulo: Malheiros, 2013, pp. 177-231. 
SUNDFELD, Carlos Ari. Como reformar as licitações? In SUNDFELD, Carlos Ari (org.). Contratações públicas e seu controle. São Paulo: Malheiros, 2013, pp. 267-276.

SUNDFELD, Carlos Ari; DE PALMA, Juliana Bonacorsi. Dinâmica de preparação do edital. In MARCATO, Fernando S.; PINTO JÚNIOR, Mário Engler. Direito da infraestrutura. Vol. 1. São Paulo: Saraiva, 2017, pp. 25-54.

TOJAL, Sebastião Botto de Barros. Interpretação do artigo 30 da Lei 12.846/13. In Revista dos Tribunais, vol. 947, set. 2014, pp 281-294.

TOJAL, Sebastião Botto de Barros; TAMASAUSKAS, Igor. A leniência anticorrupção: as primeiras aplicações, suas dificuldades e alguns horizontes para o instituto. In BOTTINI, Pierpaolo Cruz; ASSIS MOURA, Maria Thereza de. (org.). Colaboração premiada. São Paulo: Revista dos Tribunais. No prelo.

TOMAZETTE, Marlon. A administração das empresas estatais. In NORONHA, João Otávio de; FRAZÃO, Ana; MESQUITA, Daniel Augusto (Coord.) Estatuto jurídico das estatais: análise da Lei n⿳ 13.303/2016. Belo Horizonte: Fórum, 2017, pp. 141-169.

WARDE JÚNIOR, Walfrido Jorge. Legislador Frankenstein! - Não é possível transplantar governança das empresas privadas às empresas estatais. In NORONHA, João Otávio de; FRAZÃO, Ana; MESQUITA, Daniel Augusto (Coord.) Estatuto jurídico das estatais: análise da Lei n⿳0 13.303/2016. Belo Horizonte: Fórum, 2017, pp. 67-105.

WEBER, Max. Economia e sociedade: fundamentos da sociologia compreensiva. Volume 2. Brasília: Universidade de Brasília, 2004.

WING-CHI, Hui. Combating corruption: The Hong Kong experience. In Tsinghua China Law Review, vol. 6, n. 239, 2013-2014, pp. 239-256. 